\title{
Reforming Science Publishing
}

Khaled Moustafa, Editor of Arabic Science Archive (ArabiXiv)

Email: khaled.moustafa@arabixiv.org

\begin{abstract}
Over the past few years, different changes have been introduced into the science publishing industry. However, important reforms are still required at both the content and form levels. First, the peer review process needs to be open, fair and transparent. Second, author-paid fees in open access journals need to either be removed or reconsidered toward more affordability. Third, the categorization of papers should include all types of scientific contributions that can be of higher interest to the scientific community than many mere quantitative and observable measures, or simply removed from publications. Forth, word counts and reference numbers in online open access journal should be nuanced or replaced by recommended ranges rather than to be a proxy of acceptance or rejection. Finally, all the coauthors of a manuscript should be considered corresponding authors and responsible for their mutual manuscript rather than only one or two.
\end{abstract}

Keywords: science publishing, peer review bias, author responsibility, corresponding authors, word limitation, reference limitation, open access journal, publishing fees, authorship, contributorship, article processing charge, publication fees

Since the invention of the Internet in the second half of the $20^{\text {th }}$ century, the landscape of scientific publishing has witnessed major shifts in the ways we read, write, publish, retrieve, store and distribute scientific information. The Internet and personal computers offered tremendous possibilities to disseminate scientific knowledge, to facilitate communication and 
A peer-reviewed version published in Learned Publishing: https://doi.org/10.1002/leap.1315

innovation, and to bridge the information gap between developing and developed countries (Duffy 2000) (Eng 2004) (Smart 2004). Scientists from around the world use and diffuse their findings and ideas in such a way that would have been unimaginable a few decades ago. Despite these achievements, the scientific community still lacks affordable, accessible, equitable and sustainable publishing systems. There is also a paramount need to pass over some obsessions with senseless conceptions in science such as prestige and excellence (Moustafa 2016) and other refractory issues in the current academic realm (Moustafa 2014). Important reforms in the publishing system are required both at the content and form levels. Some of these are briefly discussed below.

\section{Peer review- be reviewer yourself!}

The peer review, as its name suggests, is an assessment by peers to point out any potential and detectable issues in scholarly publications. Its ultimate goal is to improve quality by filtering, which, however, can be considered a type of censorship (Smart 2020). In its proofreading and advice-giving aspects, the peer review is as old as the writing skill itself. But in its scholarly forms, the peer review is relatively recent. For example, the Journal of the American Medical Association (JAMA) did not use external reviewers until after 1940 (Spier 2002). The Lancet journal was not using peer review before 1976 as it was considered unimportant (Benos, Bashari et al. 2007). Since then, the peer review has become an essential and generalized part of science publishing particularly after the development of the Internet. Many criticisms, however, have been directed at the peer review as a time-consuming process subject to different kinds of bias. As judgments differ from an individual to another, the objectivity of evaluation by peers can be prejudiced by different personal and professional factors related to financial or non-financial conflicts of interests, unfair competition, gender bias, inconsistency, celebrity, country, institutional prestige, negative results, and avoidance of new and unconventional ideas (Smith

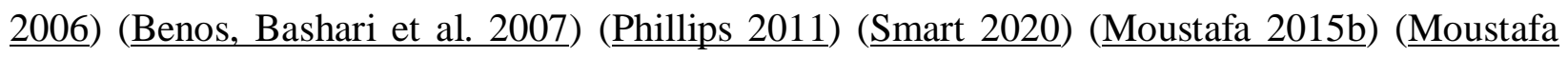
2016). No single and uniformly reliable gold standard of peer review exists so far (Baverstock 2016). The current peer review process is also an expensive business for editors, authors and publishers in terms of time and effort that should be spent on and technical infrastructure that needs to be set up and maintain for smooth and efficient work flow (Smart 2016). 
A peer-reviewed version published in Learned Publishing: https://doi.org/10.1002/leap.1315

To reduce such flaws, the peer review needs to be fair and bias-free within a good balance of quality control, transparency, flexibility, and openness. Among the potential solutions to achieve this goal are; setting up standardized procedures and reviewing protocols; training reviewers for objectivity and fairness; opening up the process; using electronic review forms and checklists; creating professional review agencies and rewarding reviewers (Smith 2006) (Phillips 2011). However, rewarding reviewers through professional agencies may raise other problems relating to the ability of journals/publishers to pay while maintaining the integrity of the process out of any potential financial conflicts of interest. In a paid peer review system, only wealthy publishers would be able to afford the costs of such a peer review choice, and small publishers or individual journals might be convicted to disappear. Publishers may also increase their subscription and/or open access fees to cover paid peer-review costs, creating additional bias sources and pressures on all the parties involved in the science publishing process (Moustafa 2014).

Another option to take into account is to harmonize the peer review for more transparency in regard with authors' and reviewers' identities that should either be disclosed for each other or undisclosed for each other, but not open for one party and closed for the other (Moustafa 2017). A further good solution to adopt to reduce peer review biases would be a light and quick form of peer review - and then let the broader audience evaluate papers by themselves (Smith 2006). This is what preprint servers are intended to do while establishing priority and providing free access to published papers. A publishing system composed of two steps in which articles are published first as preprints, and then, journal editors invite authors to submit papers that 'succeed' to peer review can also be used (Green 2019).

A strong rationale behind peer review by readers is that scholarly publishing is generally intended for informed readers and scientists who have usually sufficient or minimal scientific backgrounds in their respective fields that should allow them to read and evaluate a manuscript by themselves, be it formally peer-reviewed by journals or not. Every scientist should be a reviewer for himself in his field of specialization with critical eyes to probe the importance of what s/he reads, regardless of the judgment of other peers who might have different judgments and criteria. Moreover, publication semantically means to make something public, hence manuscripts posted on preprint servers for reading for free are implicitly and formally published materials that should be considered as is- full recognized publications. Everyone can reader 
A peer-reviewed version published in Learned Publishing: https://doi.org/10.1002/leap.1315

them, evaluate them, and judge their values. Scientists or expert readers are-should be- mature enough or trained to be able to assess what they read. Every scientist has his own or specific standards that often differ from others'. Be reviewer yourself for yourself and read with a critical eye, even papers published in the highest ranked journals.

\section{Article Processing Charge: to be discharged!}

Writing in general is a full-time job that generates money for those who practice it and sell their ideas, including the most fictional and fantasists stories, but paradoxically in the academia it is the author who should pay for the dissemination of his thoughts and results through open access outlets. This is the opposite of what knowledge is supposed to be; free of charge for readers and particularly for authors. Author-paid Open Access (OA) certainly adds a certain value to the dissemination of scientific knowledge but there is something wrong with it. A pay-to-publish model is not only exploitative but also dangerous because it makes the ability to publish contingent on the ability to pay (Kember 2016). It is more logical that readers who benefit from the ideas and thoughts of authors are those who should pay, but not the authors who spend efforts and time to offer the best of them. Author-paid publishing system looks like a farmer who works hard to produce food to feed people but he must pay further to sell his final products to consumers. Some OA journals invite authors to contribute papers while asking them to pay fees, looking like someone invites you at home to have a meal and then he asks you to pay the meal. When there is funding, it might be acceptable, but in the absence of publishing funding, OA might become problematic for authors. In some fields such as the humanities and social sciences, and in some regions of the world with limited resources for science and publishing, article processing charges (APC) are major hindrance for the dissemination of knowledge (Moustafa $\underline{2015 \mathrm{c}}$ ). OA looks likely to solve the problem of accessibility while creating a problem of affordability that many authors and institutions cannot overcome (Poynder 2014).

The current Corona Virus Disease 2019 (COVID-19) pandemic worldwide highlights the importance of open and free access and emphasizes the shortcomings of both paywall subscription and high article processing charge models for both readers and authors, respectively. Paywall models impede readers from accessing knowledge and high publishing fees hinder many authors from publishing in open access journals with high publishing fees. While papers on COVID-19 have been made open and free, information on other pandemics and incurable 
A peer-reviewed version published in Learned Publishing: https://doi.org/10.1002/leap.1315

diseases are still inaccessible while they are as deadly as the COVID-19, if not more. The sustainability of scholarly publishing may thus need to move away from both the burdensome paywalls and article processing charges-based publishing (Legge 2020). I personally think that the scientific knowledge/publishing should be a public good secured by public funds and made open and free-for-all.

It is worthy to note that before the introduction of open access journals, the acceptance motto in subscription-based journals was "novelty, quality and impact" but after the introduction of author-paid open access journals, the principle of publishing has been changed to become "technically valid and scientifically sound" papers, implying easier acceptances to increase profit margins.

What is also intriguing with open access journals is that despite the highly biased and disastrous effects of journal impact factors (JIF) (Metze 2010) (Polonioli 2016) (Towpik 2015) (Brembs, Button et al. 2013) (Bozzo, Oitment et al. 2017) (Moustafa 2015a), the publishing fees in many journals seems to be tightly associated with JIF values and popularity of fields; the high JIF value, the high publishing fees.

To keep science publishing accessible, sustainable and equitable, article processing charges should be affordable by the majority of authors with an upper threshold not to exceed even for well-funded lab to reduce the commercial dimension of science publishing. Library-based subscription and reader-pay models make more sense than author-pay models, though scientific knowledge should once again be free for authors and readers as well. As open access is turning to be a profitable industry, many traditional publishers are converting their subscription-based journals into APC-based outlets and new commercial and exploitive so-called predatory journals are mushrooming exponentially. Journals also appear to be shifting from an environment where readers are the main focus to one where -paying- authors are the target customers (Smart 2017). Open access publishing has been transformed into an open business that is hardly affordable by the majority of authors particularly in developing countries (Moustafa 2015c). The sustainability of scholarly publishing may be threatened by the dominance of one-size-fits-all open access model (Jones 2020). 
A peer-reviewed version published in Learned Publishing: https://doi.org/10.1002/leap.1315

These situations might be the consequences of dysfunction of the current academic evaluation systems and career development criteria where authors and scholars are under permanent pressures to publish always more otherwise their salaries, promotions, jobs and funding applications would be compromised. Graduate students are under pressure to publish to obtain their $\mathrm{PhD}$ degrees and faculty members are under stress to get promoted and so on. These burdens create unhealthy work atmospheres and publication frenzy that may lead to poor quality of publications, salami-slice papers, unethical practices in study design, data collection or data fabrication, and unscrupulous authorship rehearses (ghost, guests, gift, or grift authorship) to fit with academic committees' expectations. To reduce some of these distortions, publications should not be a precondition to get promoted, funded, employed, or to obtain his or her $\mathrm{PhD}$ degree. All these should be rights for everyone, but not privileges or arena of unfair competitions.

\section{Paper Categorization: prioritize content not category}

Another required reform in my view is to cease to categorize papers as to " Research Papers, Full-length papers, Original papers, Reports, Reviews, Case Studies, Case Reports, Cases Series, Letters, Commentary, Rapid, Brief or Short Communications, etc.". Otherwise, how full-length is full and how rapid communication is rapid? All articles are normally original (new or novel) including Reviews, Opinions, Commentary, etc., unless they are verbatim copies of each other, and in such a case it is a matter of plagiarism that software can detect and editors can reject. Also, not all experimental works or research articles are really original but repetitive and imitative of each other, without new, useful or applicable outputs. As the contents and overall messages of papers are the key part of publications, it does not matter much how a paper is named. Therefore, opting out of paper categorization might be a good option to consider in science publishing. Only a general denomination such as "Article" or "Paper" or "Scientific Contribution" would be enough for all the published materials.

If readers require some indices to tell them whether a paper is reporting new findings, reviewing and criticizing already existing ones or voicing opinions or suggesting new theories or conceptual studies, this normally can be seen from the title or the abstract or by default the manuscript itself. It is the relevance of a manuscript to personal or professional interests that 
A peer-reviewed version published in Learned Publishing: https://doi.org/10.1002/leap.1315

should determine the desire to read it or not, but not how it is categorized arbitrarily. Besides, the distinction between paper categories can be confusing and inconsistent between different journals and publishers. Some journals for example publish experimental findings in a format called Letters while Letters in other journals are considered Correspondences or short Letters to the Editor to comment on recently published papers, and so on.

Should paper categorization remain anyway, an essential change needs to be taken into account particularly in open access journals where only one category is currently published, often called "research papers" (or "original article"). Publishing only this type of paper suggests that open access journals are devoted exclusively or mostly on profit and money- which is true to a great extent- but not to disseminate knowledge as it is often claimed by open access proponents (Moustafa 2015c). Scientific knowledge is much larger than this subjective categorization of publications. Knowledge and scientific advancements are not limited to works or experiments on plants, microorganisms, animals and insects only, but also it includes the ability to analyze, to formulate theories, to think critically outside the box, to propose new ideas and problem-oriented solutions, etc., which can be more rewarding for the scientific community than many so-called research studies that report mere quantitative data or measures (Moustafa 2016), which might be false or irreproducible in many cases (Ioannidis 2005). The seeds of scientific and industrial revolutions were basically reflections, theories, and thoughts- before being experimental works. Furthermore, if we take the most 'selective' or 'JIF-top-ranked' journals and dig in their archives on so-called original articles back to 10, 20 or 30 years ago- to probe their impacts - what would be the percentage of "original articles" that might have some real or lasting impact, if any? Not so much compared to the high number of so-called original papers produced annually since the incarnation of "publish or perish" mantra that transformed the publishing industry into paper mills. The size of scholarly output of "original articles" is inescapably overwhelming. Nobody can follow up or read them, including specialists in their respective domains. A substantial amount of financial, human and natural resources are used to produce such hardly readable and little useful research outputs.

Additionally, the absence of article categories other than "original papers" in open access journals precludes constructive debates and reduces the possibility to challenge authors' claims, through for example, Commentaries, Opinion or Letters to the Editor. For example, the journal 
A peer-reviewed version published in Learned Publishing: https://doi.org/10.1002/leap.1315

"Science Advances" publishes only research articles and reviews (https://advances.sciencemag.org/content/information-authors). The Scientific Reports journal publishes only so-called research papers without any other types: (https://www.nature.com/srep/author-instructions/submission-guidelines). Worse, when there are some categories other than "research papers" they are often by invitation only as if science publishing was a private wedding party and only family members, friends and celebrities can be invited to. Non-research papers, however, such as Letters to the Editors, Comments, Opinions and Reviews are important parts of the science publishing landscape to counterbalance controversial claims, to foster and advance critical thinking for future research directions, and to outline or establish foundations or experiments to solve societal, biological and environmental issues.

Open access journals- as the name suggest- should be open to all types of scientific contributions but not only to one category of papers that makes journal articles annoying and almost unreadable with high and increasing rates of jargons and recycled/imitative experimental articles. Should paper categorization be kept, open access journals should once again be more inclusive to publish diverse types of scientific contributions with affordable fees rather than to be a mill of so-called research papers that the reading and comprehension are increasingly frustrating and daunting.

\section{Word limitation: eloquence in the succinctness}

To avoid receiving hugely long, rambling articles, editors and publishers set up restrictions on the length of manuscripts (word counts) and on references' numbers because many reviewers would refuse to review long articles, which tend to "waffle" and take a longer time to review. Also, readers often avoid reading long articles so they are less successful at communication than shorter and succinct papers. And longer articles are more expensive to produce (editing and typesetting costs). As such, journals specify upper word limitations not to exceed. However, word counts may lead to the truncation of some important sections, such as the Materials and Methods, into brief chunks of condensed descriptive steps that are hardly reproducible or applicable by other authors due to the lack of sufficient details on the working protocols. Some journals may consign the detailed methods as online supplementary files. Others set up word limitations as low as 1000 words or 2000 words for some kinds of contributions. Such lengths 
A peer-reviewed version published in Learned Publishing: https://doi.org/10.1002/leap.1315

might be enough in many cases, but sometimes are insufficient to address important issues or topics from different viewpoints.

To keep a good balance between and details and succinctness, online journals may need to be more flexible in regard with this matter and not to make word limitation as a rigid rule when a manuscript is some lines or paragraphs above the specified word counts. Recommendations on "preferred lengths" can eventually be given, but not to strictly make word limitation as a proxy for acceptance or rejection. Word limitation makes sense in print journals when publishers use journal templates and galleys to reproduce the same journal formats with similar number of pages for each issue, etc. But in the Internet era, word limitation would not fit much for Open Access journals, though once again succinct papers should be preferred to reduce technical and assessment burdens while emphasizing readability and rapidity of evaluation and publication compared with overly long papers.

\section{Correspondence: give it more sense!}

The corresponding author is an author who takes the responsibility for communication with a journal before, during and after the publication of manuscripts. The corresponding author is somewhat the spokesman of coauthors or a secretary acting person. S/he typically ensures that the manuscript complies with the instructions to authors, and ethical approvals are provided wherever applicable, and to verify the details of authorship, manuscripts files and raw data (tables, figures, datasets, etc.) are complete and correct. The corresponding author should be available during the submission and revisions to answer any editorial queries in due time. S/he should also be able to provide any supplementary information or missing data and to respond to collaboration requests, criticisms or any issues that may arise after publication. Although the corresponding author has primary responsibility for correspondence with a target journal, the International Committee of Medical Journal Editors (ICMJE) recommends that editors send copies of all correspondence to all the coauthors listed on a manuscript (ICMJE 2018). In most cases, the duties or responsibilities of the corresponding author are delegated to one author onlyfor technical or seniority considerations-, and in some countries, the corresponding author and/or first author was receiving high cash rewards of tens of thousands dollars when publishing in journals with high JIF values (Jufang and Huiyun 2011). Such monetary bonus systems can lure 
A peer-reviewed version published in Learned Publishing: https://doi.org/10.1002/leap.1315

researchers and lead them to commit research misconduct (Chen 2019) which seems driving China to ban it finally (Mallapaty 2020).

In addition, when only one author is designated as corresponding in multi-authored papers, contacting this author for questions or issues related to manuscript's parts he did not write, or for data he did not collect, or is unaware of, might appear challenging as he can move, change email address or simply does not wish to respond to inquiries or critiques. The absence of response in such cases might be seen as a sign of unethical behaviors or doubtful data manipulation that may threaten the validity of the reported claims.

To avoid such drawbacks, all the coauthors should in my view be assigned as corresponding by providing their email addresses on their manuscripts. Doing so, if one author does not respond to any inquiries about their manuscript for whatever reason, another author might answer, and so on. Coauthors should be collectively responsible for their manuscripts at the same title their contributions are. Obviously, for submission and during the revision stages, it is more convenient for journals and time-saving to communicate with one author only than with many. But after acceptance, all the coauthors should be deemed corresponding and responsible for their papers. The concept of one corresponding author is an old tradition maintained from print publishing systems when correspondences between journals and authors have been occurring through postal print letters. So, it was more convenient and rapid to communicate with one corresponding author than with all the coauthors. This still holds true in the Internet era, but once a paper is accepted, all the authors should be declared as corresponding by adding their contact emails on their manuscript. Correspondence in authorship should be a responsibility, but not a privilege. Being a corresponding author should not be seen as a sign or stamp of distinction or exceptional merit. All authors should be accounted for their manuscripts, and this should be made clear by providing the email addresses of all coauthors, but not only one or two. Although this might raise some privacy issues by getting spammed with undesirable emails, privacy concerns for one or many authors are the same. The roles of corresponding authors are- should- not to protect coauthors against spams but to hold responsible for their manuscripts. Privacy is a broad and persistent issue that needs be resolved at its root causes, not only for authors but in online general platforms, too. 
A peer-reviewed version published in Learned Publishing: https://doi.org/10.1002/leap.1315

Finally, it should be time to establish free, transparent, affordable, and sustainable scientific publishing systems with the most objective rules and least profit goals.

\section{References}

Baverstock, A. (2016). "Is peer review still the content industry's upper house?" Learned Publishing 29(1): 65-68.

Benos, D. J., E. Bashari, J. M. Chaves, A. Gaggar, N. Kapoor, M. LaFrance, R. Mans, D. Mayhew, S. McGowan, A. Polter, Y. Qadri, S. Sarfare, K. Schultz, R. Splittgerber, J. Stephenson, C. Tower, R. G. Walton and A. Zotov (2007). "The ups and downs of peer review." Advances in Physiology Education 31(2): 145-152.

Bozzo, A., C. Oitment, N. Evaniew and M. Ghert (2017). "The journal impact factor of orthopaedic journals does not predict individual paper citation rate." Journal of the American Academy of Orthopaedic Surgeons. Global research \& reviews $1(2)$.

Brembs, B., K. Button and M. Munafo (2013). "Deep impact: unintended consequences of journal rank." Front Hum Neurosci 7: 291.

Chen, X. (2019). "High Monetary Rewards and High Academic Article Outputs: Are China's Research Publications Policy Driven?" The Serials Librarian 77(1-2): 49-59.

Duffy, M. (2000). "The Internet as a research and dissemination resource." Health Promotion International 15(4): 349-353.

Eng, T.-Y. (2004). "Implications of the Internet for Knowledge Creation and Dissemination in Clusters of Hi-tech Firms." European Management Journal 22(1): 87-98.

Green, T. (2019). "Is open access affordable? Why current models do not work and why we need internet-era transformation of scholarly communications." Learned Publishing 32(1): 13-25.

ICMJE, I. C. o. M. J. E., S (2018). Recommendations for the conduct, reporting, editing, and publication of scholarly work in medical journals.

Ioannidis, J. P. (2005). "Why most published research findings are false." PLoS Med 2(8): e124.

Jones, P. (2020). "A report on the future of independent and scholarly publishing webinar by the Scholarly Kitchen." Learned Publishing 33(1): 43-46.

Jufang, S. and S. Huiyun (2011). "The outflow of academic papers from China: why is it happening and can it be stemmed?" Learned Publishing 24(2): 95-97.

Kember, S. (2016). "Why publish?" Learned Publishing 29(S1): 348-353. 
A peer-reviewed version published in Learned Publishing: https://doi.org/10.1002/leap.1315

Legge, M. (2020). "Towards sustainable open access: A society publisher's principles and pilots for transition." Learned Publishing 33(1): 76-82.

Mallapaty, S. (2020). "China bans cash rewards for publishing papers." Nature 579(7797): 18-18. Metze, K. (2010). "Bureaucrats, researchers, editors, and the impact factor: a vicious circle that is detrimental to science." Clinics 65(10): 937-940.

Moustafa, K. (2014). "Don't fall in common science pitfall!" Front Plant Sci 5: 536.

Moustafa, K. (2015a). "The disaster of the impact factor." Sci Eng Ethics 21(1): 139-142.

Moustafa, K. (2015b). "Is there bias in editorial choice? Yes." Scientometrics 105(3): 2249-2251.

Moustafa, K. (2015c). "Open access, open business, closed fairness!" Account Res 22(4): 246-248.

Moustafa, K. (2016). "Publishing, Objectivity, and Prestige." J Microbiol Biol Educ 17(3): 331-332.

Moustafa, K. (2017). "Peer review: either open it fully or blind it wholly." Int J Dermatol 56(4): e86.

Phillips, J. S. (2011). "Expert bias in peer review." Current Medical Research and Opinion 27(12): 22292233.

Polonioli, A. (2016). "Metrics, flawed indicators, and the case of philosophy journals." Scientometrics 108(2): 987-994.

Poynder, R. (2014). "Open access: What price affordability?" Ecancermedicalscience 8: ed41-ed41.

Smart, P. (2004). "International Network for the Availability of Scientific Publications: facilitating scientific publishing in developing countries." PLoS biology 2(11): e326-e326.

Smart, P. (2016). "Peer review: An expensive business." Learned Publishing 29(1): 3-4.

Smart, P. (2017). "Readers - what readers?" Learned Publishing 30(4): 255-257.

Smart, P. (2020). "Is filtering censorship?" Learned Publishing 33(2): 86-87.

Smith, R. (2006). "Peer review: a flawed process at the heart of science and journals." Journal of the Royal Society of Medicine 99(4): 178-182.

Spier, R. (2002). "The history of the peer-review process." TRENDS in Biotechnology 20(8): 357-358.

Towpik, E. (2015). "IF-mania: Journal Impact Factor is not a proper mean to assess the quality of research, individual researchers, nor scientific institutions." Nowotwory. Journal of Oncology 65(6): 465475. 